\begin{tabular}{c|c|c|} 
SELECCIONES MATEMÁTICAS \\
Universidad Nacional de Trujillo \\
ISSN: $2411-1783$ (Online) \\
2021; Vol. $8(2): 218-227$.
\end{tabular}

\title{
On the numerical solution of a mathematical model for the concrete carbonation with a non-uniform diffusivity coefficient
}

\section{Sobre la solución numérica de un modelo matemático para la carbonatación del concreto con coeficiente de difusividad no uniforme}

\author{
Marcos Zambrano F. (1)
}

Received, Jul. 31, 2021

Accepted, Set. 30, 2021

How to cite this article:

Zambrano, Marcos. On the numerical solution of a mathematical model for the concrete carbonation with a nonuniform diffusivity coefficient. Selecciones Matemáticas. 2021;8(2):218-227. http://dx. doi .org/10.17268/ sel.mat.2021.02.01

\begin{abstract}
In this research, a mathematical model to determine the concentration of concrete carbonation is investigated using several numerical schemes which provide the distribution of carbonation in a concrete region. This model considers an Arrhenius-type relation which implies a non-uniform diffusion coefficient for a reaction-diffusion problem in the model. To perform the computations of the model investigated, the finitedifferences and finite-volume methods are employed which are implemented in the mathematical software GNU-Octave and the finite-volume software OpenFOAM respectively.
\end{abstract}

Keywords . Concrete carbonation, reaction-diffusion problem, finite difference method, volume finite method.

\section{Resumen}

En esta investigación, un modelo matemático para determinar la concentración de carbonatación del concreto es investigado usando diversos esquemas numéricos que proveen una distribución de la carbonatación en la región del concreto. Este modelo considera una relación de Arrhenius lo que lleva a un coeficiente de difusión no uniforme para un problema de reacción-difusión en el modelo. Para el desarrollo de los cálculos numéricos del modelo investigado, los métodos de diferencias finitas y volumenes finitos son empleados los cuales se implementan en el software matemático GNU-Octave y el software de volumen finito OpenFOAM respectivamente.

Palabras clave. Carbonatación del concreto, problema de reacción-difusión, método de diferencia finita, método de volumen finito.

1. Introduction. Concrete carbonation is a chemical reaction between carbon dioxide $(\mathrm{CO})_{2}$ and calcium hydroxide $\mathrm{Ca}(\mathrm{OH})_{2}$ found in the existing concrete in the construction of buildings, bridges, etc. In this reaction calcium carbonate $\mathrm{CaCO}_{3}$ and water $\mathrm{H}_{2} \mathrm{O}$ is produced according to

$$
\mathrm{CO}_{2}(g \rightarrow a q)+\mathrm{Ca}(\mathrm{OH})_{2}(s \rightarrow a q) \longrightarrow \mathrm{CaCO}_{3}(a q \rightarrow s)+\mathrm{H}_{2} \mathrm{O} .
$$

This process occurs continuously when $\mathrm{CO}_{2}$ existing in the air of the atmosphere penetrates into concrete whose solution highly alkaline with a $\mathrm{pH} \approx 14$ leading a decreasing its $\mathrm{pH}$ level[3]. This way, the oxide layer which surrounding the steel reinforcements in the concrete disappears leading to the corrosion of the steel. This situation affects the durability of the structure by increasing the portion of steel which produces a further fracture of the structure. Figure 1.1 shows the reinforcement steel exposed to the carbonatation of concrete; a situation commonly found in structures actually.

*Departamento Académico de Ciencias Básicas y Afines, Universidad Nacional de Barranca, Lima, Perú. (mzambrano@unab. edu.pe). 
The mechanism of transport of $\mathrm{CO}_{2}$ in the carbonation process produces many reactions [3] and thus this process can be complex involving a large number of factors to determine the depth of carbonation in time, for which the predictibility of a model that allows to find the amount of carbonation in concrete can be questionable. However, since the mechanisms of this process are well known, to investigate the formulation of minimal models to determine the depth and the amount of $\mathrm{CO}_{2}$ existing in the concrete turns out to be interesting and this is the premise of the present paper.

The layout of the paper is the following; in section 2, a mathematical formulation of the concentration of $\mathrm{CO}_{2}$ in the concrete is formulated; in section 3, a nondimensionalization of the model regarding an diffusivity coefficient either constant or non-uniform is carried out; in section 4, data presented in [9] are used to determine the reaction coefficient in the model. In section 5 , the numerical schemes for finitevolume and finite-difference are explained and the procedure to perform the numerical computation by the OpenFOAM solver on region of concrete is mentioned; in section 6, the results obtained in the computations are shown to highlight the influence of a non-uniform diffusivity coefficient in the mathematical model. The discussion and conclusion are drawn in section 7.

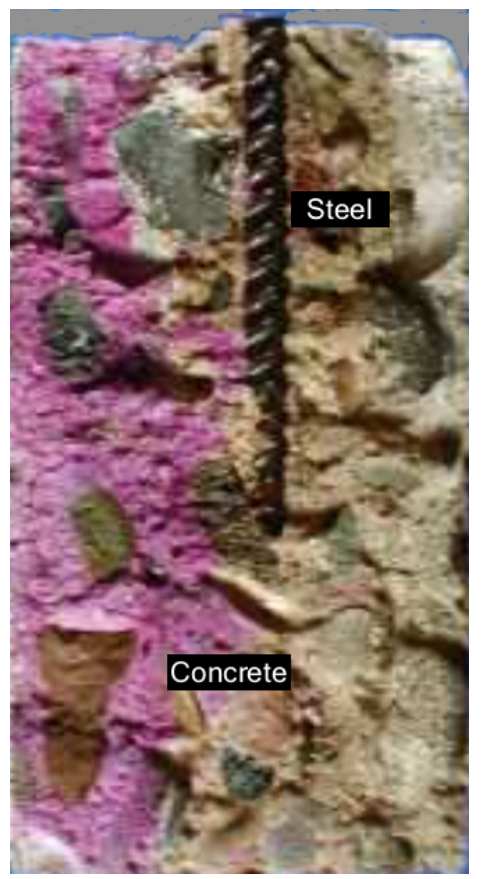

Figure 1.1: Carbonation of concrete (adapted from [5])

2. Mathematical formulation. Consider a square region of concrete with length $2 L$ and exposed to $\mathrm{CO}_{2}$ from the air, whose center contains a cylindrical steel reinforcement so that by a symmetry can be depict as in figure 2.1 is shown. Thus, to describe the $\mathrm{CO}_{2}$-concentration $c=c(x, y, t)$ with diffusivity coefficient $D=D(c)$, where $x, y$ denote the horizontal and vertical coodinates respectively and $t$ denotes the time, the following reaction-diffusion equation is considered

$$
\frac{\partial c}{\partial t}=\frac{\partial}{\partial x}\left(D \frac{\partial c}{\partial x}\right)+\frac{\partial}{\partial y}\left(D \frac{\partial c}{\partial y}\right)-R(c)
$$

where $R(c)$ is the reaction term which depends on $c$.

For the diffusivity coefficient, an Arrhenius-type expression

$$
D(c)=D_{c}\left\{1-\exp \left(-\frac{\mu}{c}\right)\right\}
$$

where $D_{c}$ and $\mu>0$ are constant numeric values considered and the reaction term is explicity given by

$$
R(c)=k c,
$$

where $k>0$. 


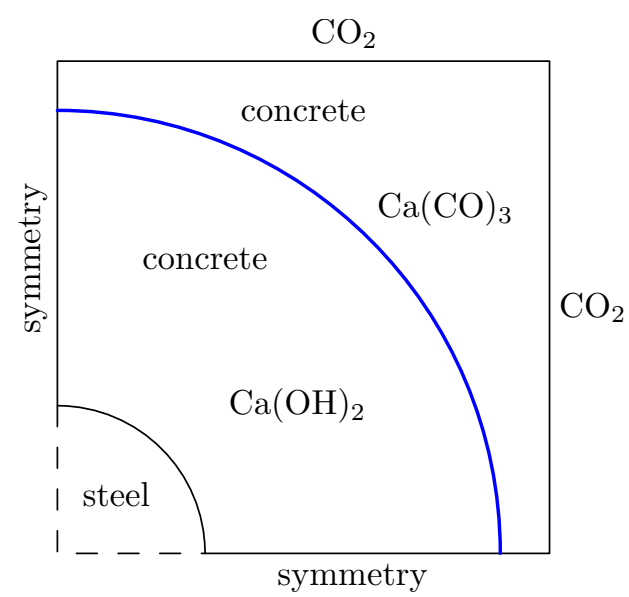

Figure 2.1: Schematic of the process of carbonation

To prescribe the boundary conditions, the boundaries considered are shown in figure 2.1 ; for the symmetry boundaries: at $x=0$

$$
\frac{\partial c}{\partial x}=0
$$

and at $y=0$,

$$
\frac{\partial c}{\partial y}=0
$$

also for the boundaries exposed at the air wherein the constant concentration of $\mathrm{CO}_{2}$ is given by $\tilde{c}$; the boundary conditions are: at $x=L$,

$$
c=\tilde{c}
$$

at $y=L$,

$$
c=\tilde{c} .
$$

Besides, at the interface steel-concrete, denoted by $\Gamma(x, y)=0$, the boundary condition is given by

$$
\frac{\partial c}{\partial \hat{n}}=0
$$

where $\hat{n}$ is the unit vector normal to the interface steel-concrete.

Also, the initial condition is given by $c(x, y, 0)=0$.

3. Nondimensionalization. Using the nondimensionalization

$$
c^{*}=\frac{c}{\tilde{c}}, x^{*}=\frac{x}{L}, y^{*}=\frac{y}{L}, t^{*}=\frac{t}{L^{2} / D_{c}} .
$$

Equation (2.1) becomes

$$
\frac{\partial c^{*}}{\partial t^{*}}=\frac{\partial}{\partial x^{*}}\left(\tilde{D}\left(c^{*}\right) \frac{\partial c^{*}}{\partial x^{*}}\right)+\frac{\partial}{\partial y^{*}}\left(\tilde{D}\left(c^{*}\right) \frac{\partial c^{*}}{\partial y^{*}}\right)-k^{*} c^{*}
$$

where for $\mu^{*}=\mu / \tilde{c}$

$$
\tilde{D}\left(c^{*}\right)=1-\exp \left(-\frac{\mu^{*}}{c^{*}}\right)
$$

and

$$
k^{*}=\frac{k L^{2}}{D_{c}},
$$


and the boundary conditions (2.4)-(2.8) becomes respectively

$$
\frac{\partial c^{*}}{\partial x^{*}}=0
$$

at $x^{*}=0$,

$$
\frac{\partial c^{*}}{\partial y^{*}}=0
$$

at $y^{*}=0$,

$$
c^{*}=1
$$

at $x^{*}=1$,

$$
c^{*}=1
$$

at $y^{*}=1$.

Also, (2.8) becomes

$$
\frac{\partial c^{*}}{\partial \hat{n}^{*}}=0
$$

at $\Gamma^{*}\left(x^{*}, y^{*}\right)=0$ and the initial condition is given by $c^{*}\left(x^{*}, y^{*}, 0\right)=0$.

4. Analysis. Using data, presented in [9],

$$
\tilde{c} \sim 7 \times 10^{-4} \mathrm{~kg} \mathrm{~m}^{-3}, D_{c} \sim 10^{-11} \mathrm{~m}^{2} \mathrm{~s}^{-1}, k \sim 10^{-10} \mathrm{~s}^{-1}, L \sim 10^{-1} \mathrm{~m},
$$

the reaction coefficient becomes now

$$
k^{*} \sim 0.1
$$

but from (3.3), clearly

$$
\tilde{D} \rightarrow 1 \quad \text { as } \quad c^{*} \rightarrow 0
$$

which implies that (3.2) becomes

$$
\frac{\partial c^{*}}{\partial t^{*}}=\frac{\partial^{2} c^{*}}{\partial x^{* 2}}+\frac{\partial^{2} c^{*}}{\partial y^{* 2}}-k^{*} c^{*} .
$$

Thus, there are two cases; a first case considers the diffusivity coefficient uniform or constant, namely $D(c)=D_{c}$ as shown in equation (4.3) and a second case occurs when $D(c)$ depends on an Arrheniustype relation which lead to equation (3.2). In addition, these two earlier cases can be investigated in onedimension $[3,9,8]$ which can be expressed as

$$
\frac{\partial c^{*}}{\partial t^{*}}=\frac{\partial}{\partial x^{*}}\left(\tilde{D} \frac{\partial c^{*}}{\partial x^{*}}\right)-k^{*} c^{*},
$$

from equation (3.2) and

$$
\frac{\partial c^{*}}{\partial t^{*}}=\frac{\partial^{2} c^{*}}{\partial x^{* 2}}-k^{*} c^{*}
$$

from equation (4.3) whose boundaries conditions are prescribed at $x^{*}=0$ and $x^{*}=1$ with

$$
\frac{\partial c^{*}}{\partial x^{*}}=0
$$

on $x^{*}=0$ and

$$
c^{*}=1
$$

on $x^{*}=1$ and the initial condition $c^{*}\left(x^{*}, 0\right)=0$. 
5. Numerical implementation. To perform numerical computations aiming to find the concentration of $\mathrm{CO}_{2}$, the one-dimensional equations (4.4) and (4.5) were solved using the programming lenguage GNUOctave [4] was employed to implement the finite volume and finite difference methods. For this, a regular partition of $N$ cells of the interval $[0,1]$ whose ends are given by $x_{0}^{*}, x_{1}^{*}, \ldots, x_{N}^{*}$ is defined and the centers of the cells are given by $x_{1 / 2}^{*}, \ldots, x_{N-1 / 2}^{*}$. The value of $c$ in these centers are respectively $c_{1 / 2}^{*}, \ldots, c_{N-1 / 2}^{*}$. The finite volume method [7] is based in the average of $c^{*}$-value in each cell of the $h$-norm partition given by

$$
c_{i+1 / 2}^{*}=\frac{1}{h} \int_{x_{i}^{*}}^{x_{i+1}^{*}} c^{*}\left(x^{*}, t^{*}\right) \mathrm{d} x^{*},
$$

for $i=0, \ldots, N-1$. Thus, equation (4.4) is discretized to become

$$
h \frac{c_{i+1 / 2}^{* n+1}-c_{i+1 / 2}^{* n}}{\Delta t^{*}}=\tilde{D}_{i+1} \frac{c_{i+3 / 2}^{* n+1}-c_{i+1 / 2}^{* n+1}}{h}-\tilde{D}_{i} \frac{c_{i+1 / 2}^{* n+1}-c_{i-1 / 2}^{* n+1}}{h}-k h c_{i+1 / 2}^{* n+1},
$$

where $\Delta t^{*}$ is the step of time for every iteration. Also, for $\tilde{D} \sim 1$, the finite difference scheme [1] allows to write equation (4.5) as

$$
\frac{c_{i}^{* n+1}-c_{i}^{* n}}{\Delta t^{*}}=\frac{c_{i-1}^{* n+1}-2 c_{i}^{* n+1}+c_{i+1}^{* n+1}}{h^{2}}-k c_{i}^{* n+1} .
$$

For the two-dimensional case, equations (3.2) and (4.3) were solved by the OpenFOAM software [10], which is freely distributed. To carry out the numerical computations to obtain the $c^{*}$ values in this case, is importante, initially, to mesh the region of concrete wherein (3.2) and (4.3) will be solved; and which is in nondimensionalized coordinates in this case. This mesh process is carried out using an utility available in the OpenFOAM software called blockMeshdict.

In figure 5.1 is shown the mesh obtained from the utility blockMeshdict. Once the mesh is defined, solver to obtain the solution to (3.2) and (4.3), a solver called carFoam built from the tools available in the OpenFOAM software. The solver carFoam is built based on the scheme

$$
\text { fvm :: } \operatorname{ddt}(\mathrm{C})-\mathrm{fvm}:: \operatorname{laplacian}(\mathrm{D}, \mathrm{C})-\mathrm{k} * \mathrm{C},
$$

where fvm is implicit representation of magnitude to compute.

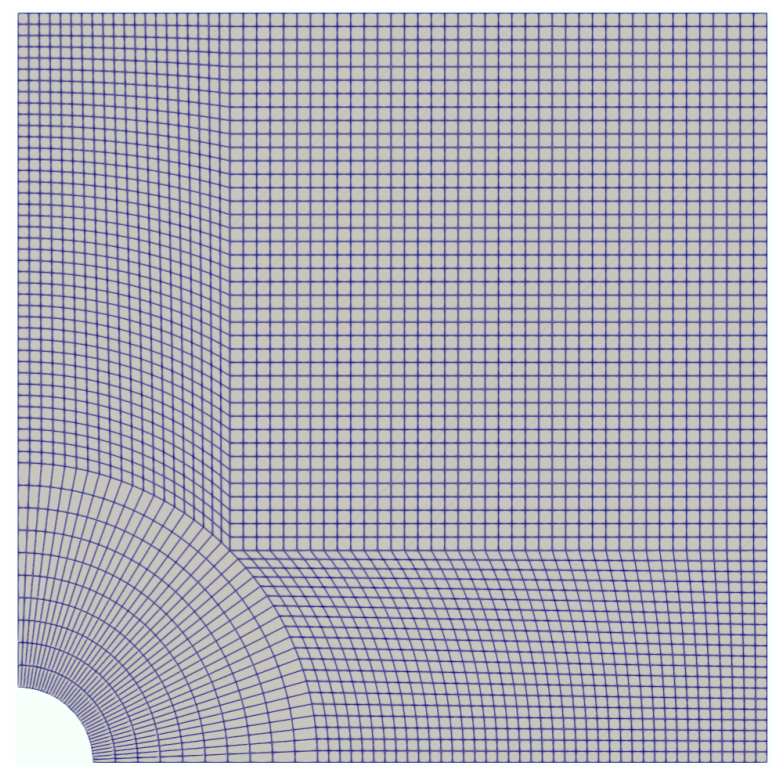

Figure 5.1: Mesh for concrete carbonation

In addition, (5.4) can be expressed as

$$
\frac{C^{* n+1}-C^{* n}}{\Delta t^{*}}=\nabla \cdot\left(D \nabla C^{* n+1}\right)-k * C^{* n+1},
$$

where $C^{* n}$ is the vector containing the values at time $t^{*}=t^{* n}$ and $\Delta t^{*}$ is the step of time in every iteration to compute $C^{* n+1}$ from $C^{* n}$. 
6. Results. Initially, the one-dimensional case expressed by (4.4) and (4.5) were implemented in GNU-Octave programming lenguage and the results are shown in figure 6.1 wherein the solution to (4.4) is obtained using the finite-volume method for two values $\mu^{*}=0.5$ and $\mu^{*}=1.0$ and these are compared with the solution to (4.5) which has the diffusivity coefficient uniform or constant being suitable to employ the finite difference method as done. From this, the greater value of $\mu^{*}$ implies that the concentration of carbonation of concrete obtained is closer to that where the diffusivity coefficient is uniform.

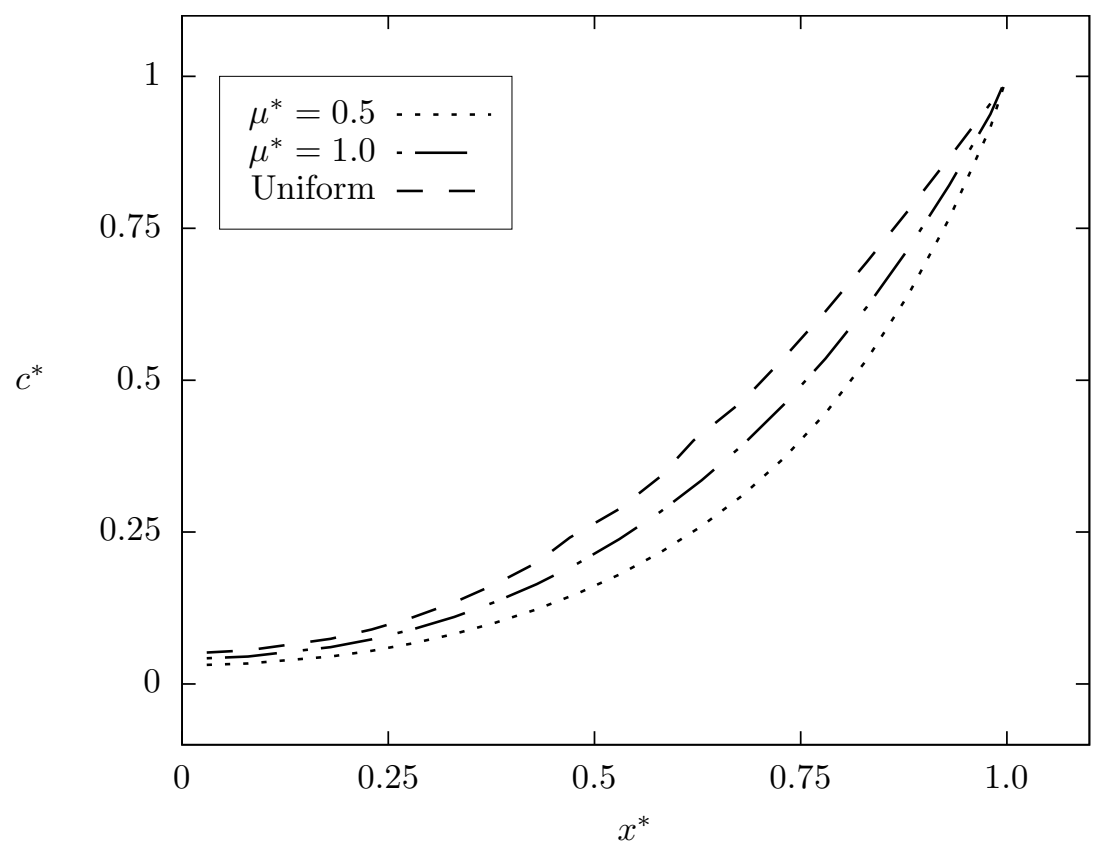

Figure 6.1: One-dimensional concrete carbonation for a nonuniform diffusivity coefficient with values $\mu^{*}=0.5,1$ vs a constant diffusivity coefficient at $t^{*}=0.1$

Solution to (3.2) is obtained by carFoam solver from the OpenFOAM software and the results are shown in figure 6.2 wherein a progressive level of concentration of carbonation is spreading in the region of concrete and the level of concentration of carbonation at the boundaries $x^{*}=1$ or $y^{*}=1$ is constant with $c^{*}=1$.

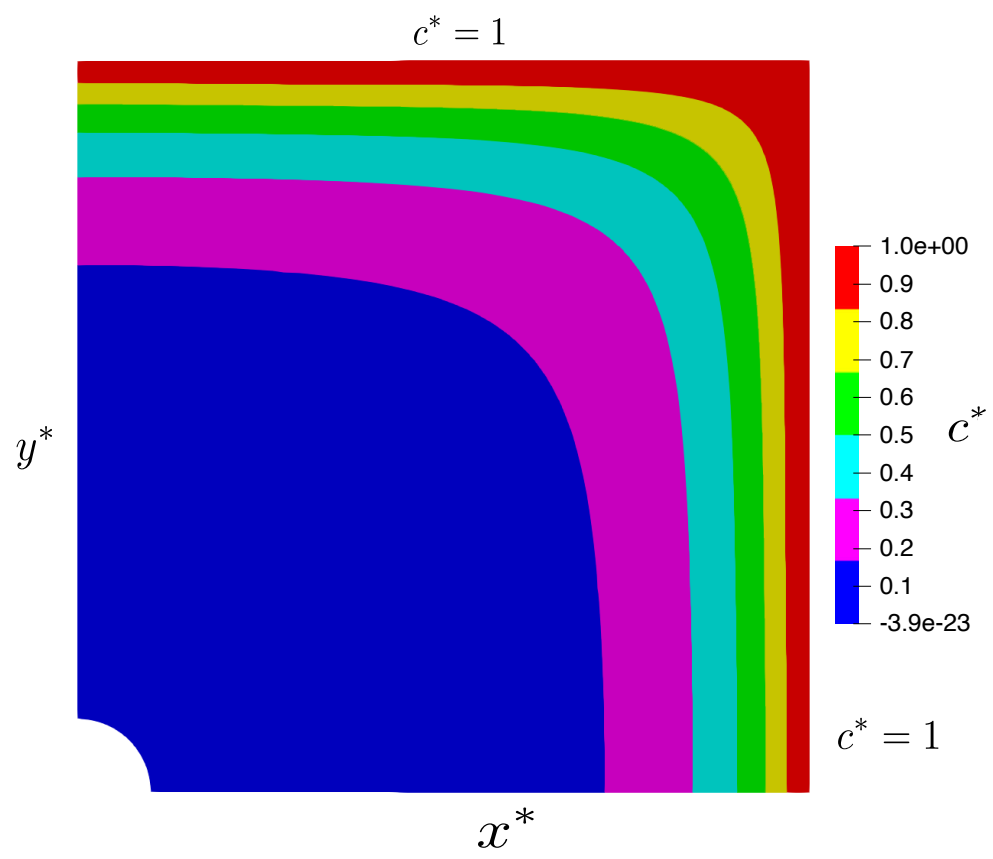

Figure 6.2: Concrete carbonation at $t^{*}=0.1$ using nonuniform diffusion coefficient determined by $\mu^{*}=1$. 
Regarding only the diffusion of carbonation through the $x$ - axis or $y$ - axis can shed lights about how fast the concentration of carbonation is present in these axis and this is shown in figure 6.3 wherein the concentration is observed along the $x$ - axis for the three different values $t^{*}=0.01, t^{*}=0.05$ and $t^{*}=0.10$; clearly is shown an increasing level of concentration with $t^{*}$.

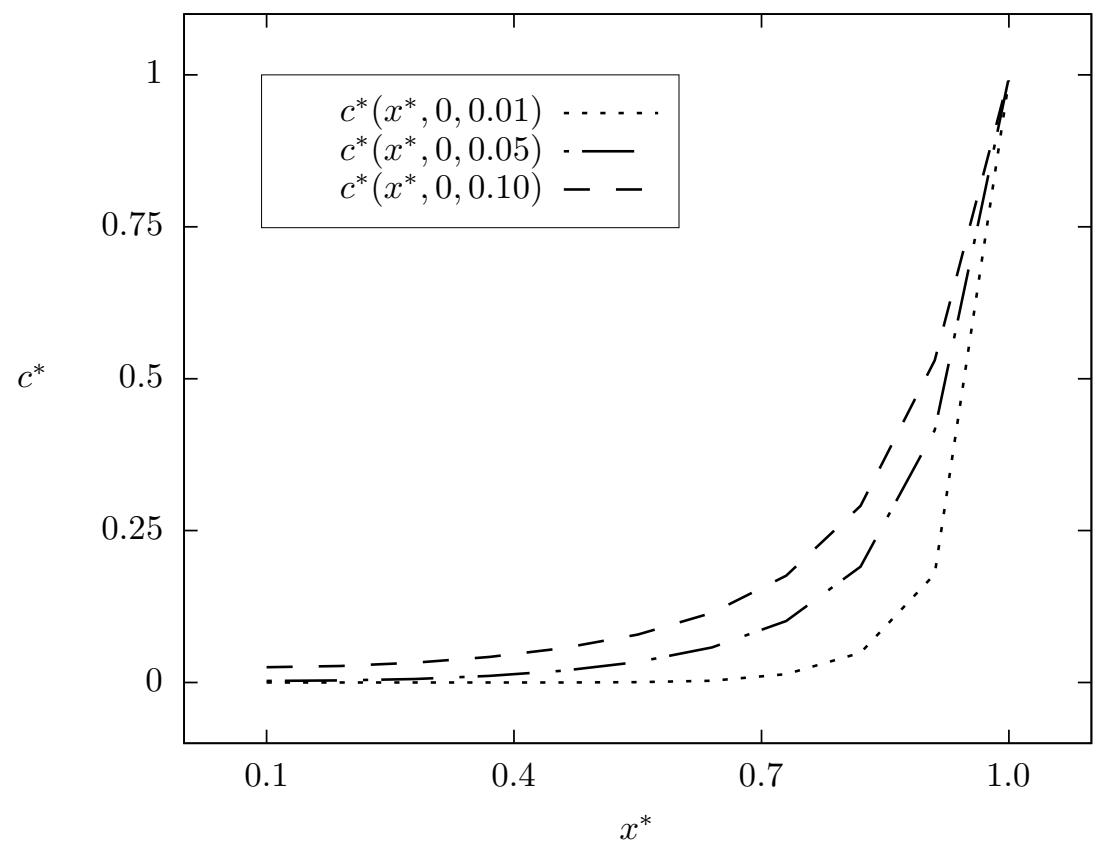

Figure 6.3: Dependence on nonuniform diffusivity in the $x$ - axis for the three different values $t^{*}=0.01$, $t^{*}=0.05$ and $t^{*}=0.10$.

Similarly, solution to equation (4.3) which describes a uniform diffusivity coefficient can be observed only in $x$ - axis and this is shown in figure 6.4 for the three different values $t^{*}=0.01, t^{*}=0.05$ and $t^{*}=0.10$ wherein the concentration of carbonation is larger than that shown in figure 6.3 .

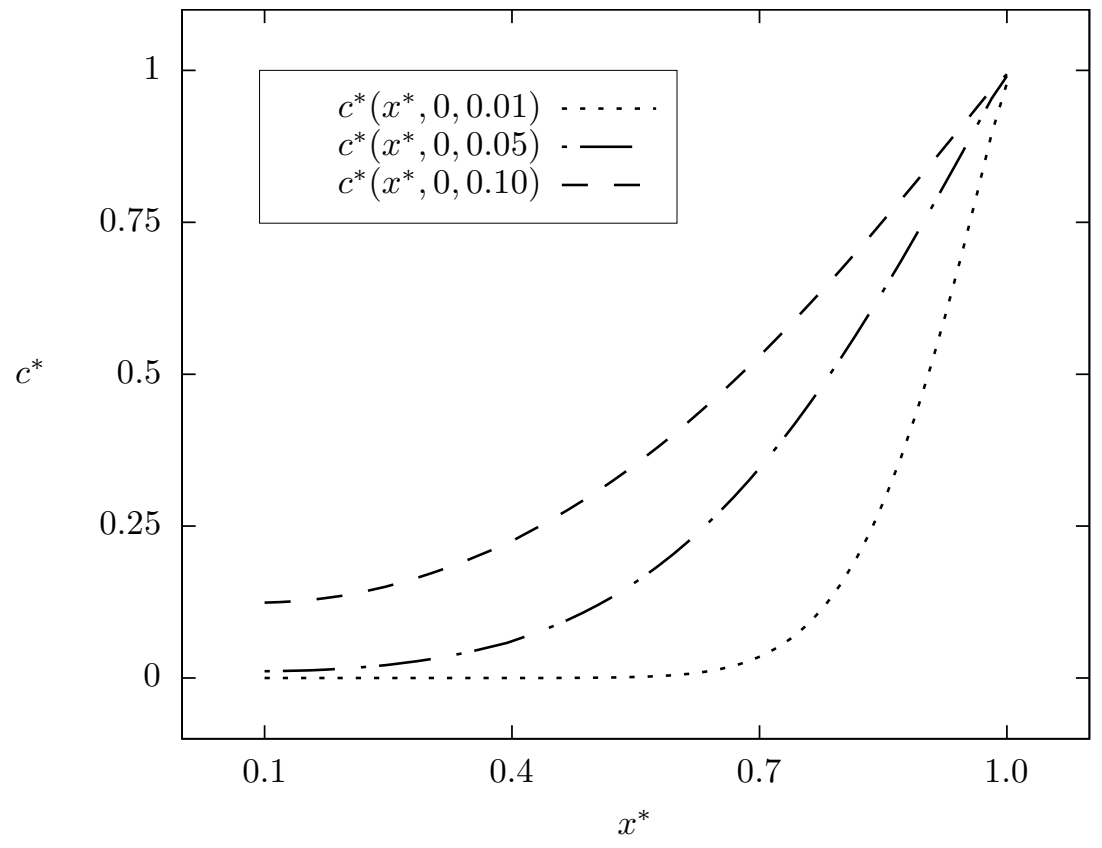

Figure 6.4: concrete carbonation with uniform diffusivity in the $x$ - axis for the three different values $t^{*}=0.01, t^{*}=0.05$ and $t^{*}=0.10$.

Finally, in figure 6.5 is shown the level of concentration of carbonation along the $x$-axis from the solution to equation (3.2) and how the diffusivity coefficient dependence on $\mu^{*}$ is reflected on the concentration 
of carbonation.

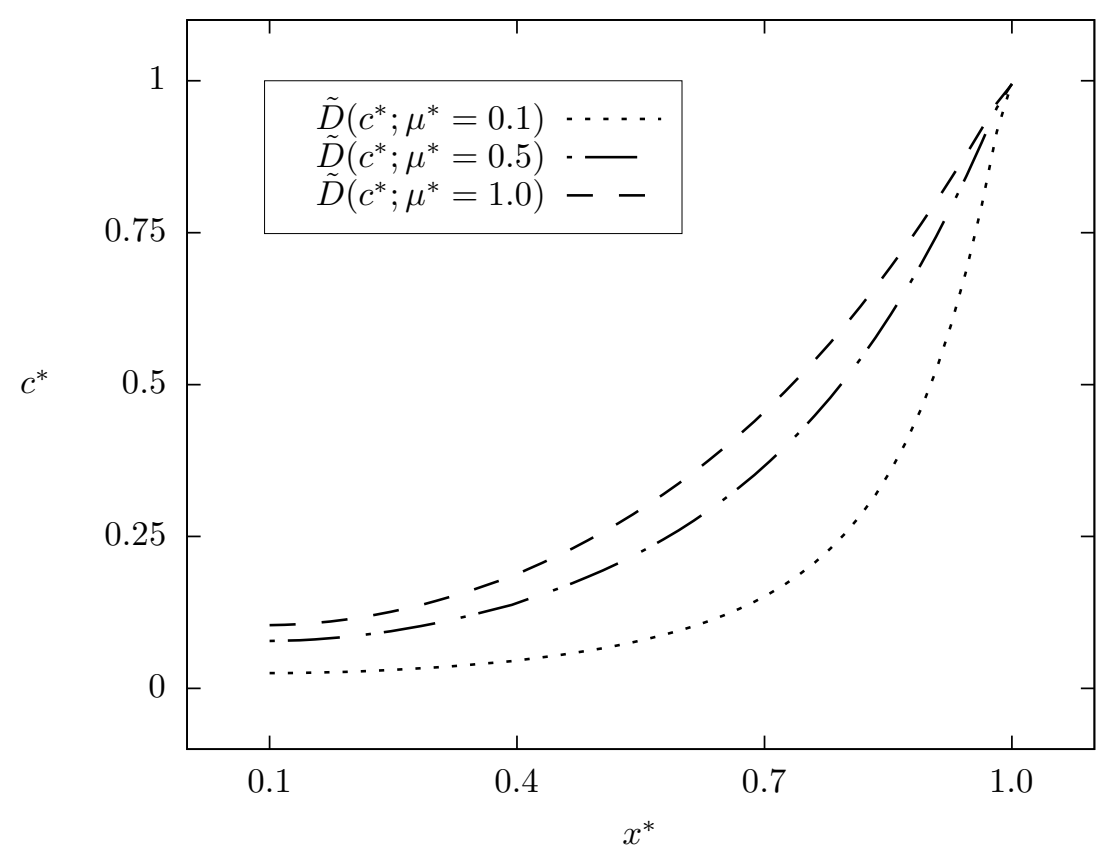

Figure 6.5: Dependence on $\mu^{*}$ for the diffusivity coefficient in the concentration of carbonation along the $x$-axis for the three different values $\mu^{*}=0.1, \mu^{*}=0.5$ and $\mu^{*}=1.0$.

Finally, it is important to mention that some values of $t^{*}$ corresponds to some values of $t$ via the expression $t=t^{*} L^{2} / D_{c}$, thus $t^{*}=0.1$ gives $t=\frac{0.1(0.1)^{2}}{10^{-11}} \sec \approx 3$ years.

7. Discussion and Conclusions. In this paper, a mathematical model with a nonuniform difusivity coefficient $D(c)$ has been presented wherein $D(c)$ according to [2, 3] can be expressed by an Arrhenius law, although some authors [13] expressed an Arrhenius law related to the temperature found in the region of concrete, in this paper is related to the concentration $c$. To obtain a nondimensionalized form of the original equation (2.1) was necessary to take as reference the concentration of carbonation at which the concrete is exposed at the air, say $\tilde{c}$, this way, once obtained (3.2), the boundary condition at $x^{*}=1$ was $c^{*}=1$; the model defined by an reaction-diffusion equation (3.2) was an akin to that usually found in literature for the heat transfer [12, 2].

Although there exist several models for carbonation of concrete as the model presented by Papadakis et al. [11] wherein many factors are considered as water-cement ratio, relativity humidity and so on; in this paper a simple model for the carbonation of concrete $[9,3]$ has been considered to gain some insights of the process involved when a nonuniform diffusivity coefficient is added.

To solve equations (3.2) and (4.4) were solved using the finite-volume methods, which is actually employed to solve equations in which the fluxes must be conserved [7] and in this case a nonuniform diffusivity coefficient has been considered. On the other hand equations (4.3) and (4.5) were solved by the finite-volume method and the finite difference method [6, 1], but from (4.3) was shown the concentration of carbonation on a boundary.

To solve equations (3.2) and (4.3), using the finite-volume method was employed a customize solver name carFoam built from the OpenFOAM software whilst equations (4.4) and (4.5) were solved using the GNU-Octave programming lenguage [4]; which allowed to implement the finite-volume as described in appendix A and finite difference methods using the algorithms shown in appendix B.

For a further investigation, it is suitable to uncover algorithms and computational implementations which allow to determine the front of the carbonation in the concrete as those found by $\mathrm{Li}$ et al. [8] to determine the front or the techniques found in the moving boundary problems.

8. Acknowledgements. The author thanks Dra. Marialita C. Ramírez for the support, patience and unvaluable advices during several months in which the present paper was written.

\section{ORCID and License}

Marcos Zambrano F. https: / / orcid.org/0000-0002-4327-9000 


\section{References}

[1] Burden R, Faires J. Numerical Analysis, 3rd. ed., Brooks/Cole, 2012.

[2] Dantzig JA, Tucker C. Modeling in Materials Processing, 1st ed., Cambridge University Press, 2001.

[3] Evans JD, Fernández A. Sharp-Interface Models for Concrete Carbonation. Numerical Analysis and Applied Mathematics ICNAAM, AIP American Institute of Physics, 2012.

[4] Eaton J, Bateman D, Hauberg S, Wehbring R. GNU Octave version 5.2.0 manual: a high-level interactive language for numerical computations. 2020.

[5] Evans JD, Fernández A, Muntean A. Single and two-scale sharp-interface models for concrete carbonation - Asymptotics and numerical approximation Multiscale Model. Simul. SIAM, 2012; 10(3):874-905.

[6] Leveque RJ. Finite Difference Methods for Ordinary and Partial Differential Equation, 1st ed., Society for Industrial and Applied Mathematics (SIAM), 2007.

[7] Leveque RJ. Finite Volume Methods for Hyperbolic Problems, Cambridge University Press, 2002.

[8] Li D, Li LY, Wang X. Mathematical modelling of concrete carbonation with moving boundary. International Communications in Heat and Mass Transfer, 2020; 117: 104809.

[9] Ming-Te L, Shieng-Min L. Mathematical Modeling and Applications for concrete carbonation. Journal of Marine Science and Technology. 2003; 11:20-33.

[10] OpenFOAM foundation. OpenFOAM - Field Operation and Manipulation. 3rd edition, Elsevier Science, 2012.

[11] Papadakis VG, Vayenas CG, Fardis MN. Fundamental Modeling and Experimental Investigation of Concrete Carbonation, ACI Materials J. 1991; 88(4):363-373.

[12] Pletcher R. Computational Fluid Mechanics and Heat Transfer, 3th. edition, CRC. Press; 1997.

[13] Steffens A, Dinkler D, Ahrens H. Modeling carbonation for corrosion risk prediction of concrete structures Cement and Concrete Research, Pergamon. 2002; 32:935-941.

\section{Appendix A. Implementation of finite-volume method.}

To obtain solution equation (4.4), the finite-volume method was employed and an implementation in GNU-Octave was carried out via the programming of functions which are possible to code.

In Algorithm 1, the function is named FINITEVOLCARBONATION and retrieve six arguments, which are: $c$ the initial concentration of carbonation existing in the region of concrete, $N$ the number of cells in the region of concrete, $\gamma$ the ratio $d t / d x^{2}, \mu$ the coefficient in the nonuniform diffusivity coefficient, $k$ the reaction term coefficient and $N_{t}$ the number of iterations in time.

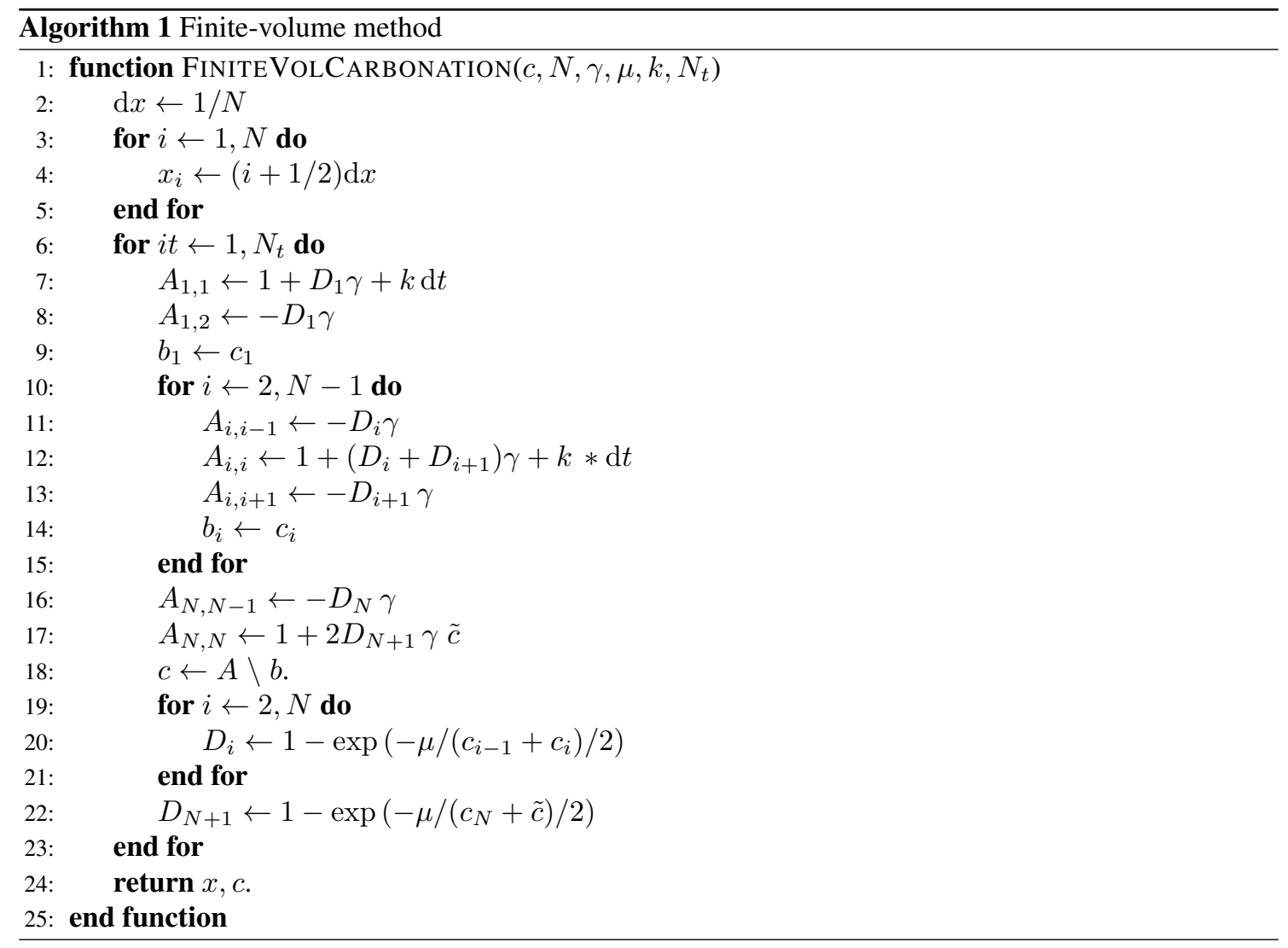




\section{Appendix B. Implementation of finite-difference method.}

To solve equation (4.4), the finite-difference method was employed to implement a code in the programming lenguage GNU-Octave via the difinition of a function named FINITEDIFFCARBONATION shown in Algorithm 2 which retrieve five arguments, which are: $c$ the initial concentration of carbonation existing in the region of concrete, $N$ the number of nodes in the region of concrete, $\gamma$ the ratio $d t / d x^{2}, k$ the reaction-term coefficient and $N_{t}$ the number of iterations in time.

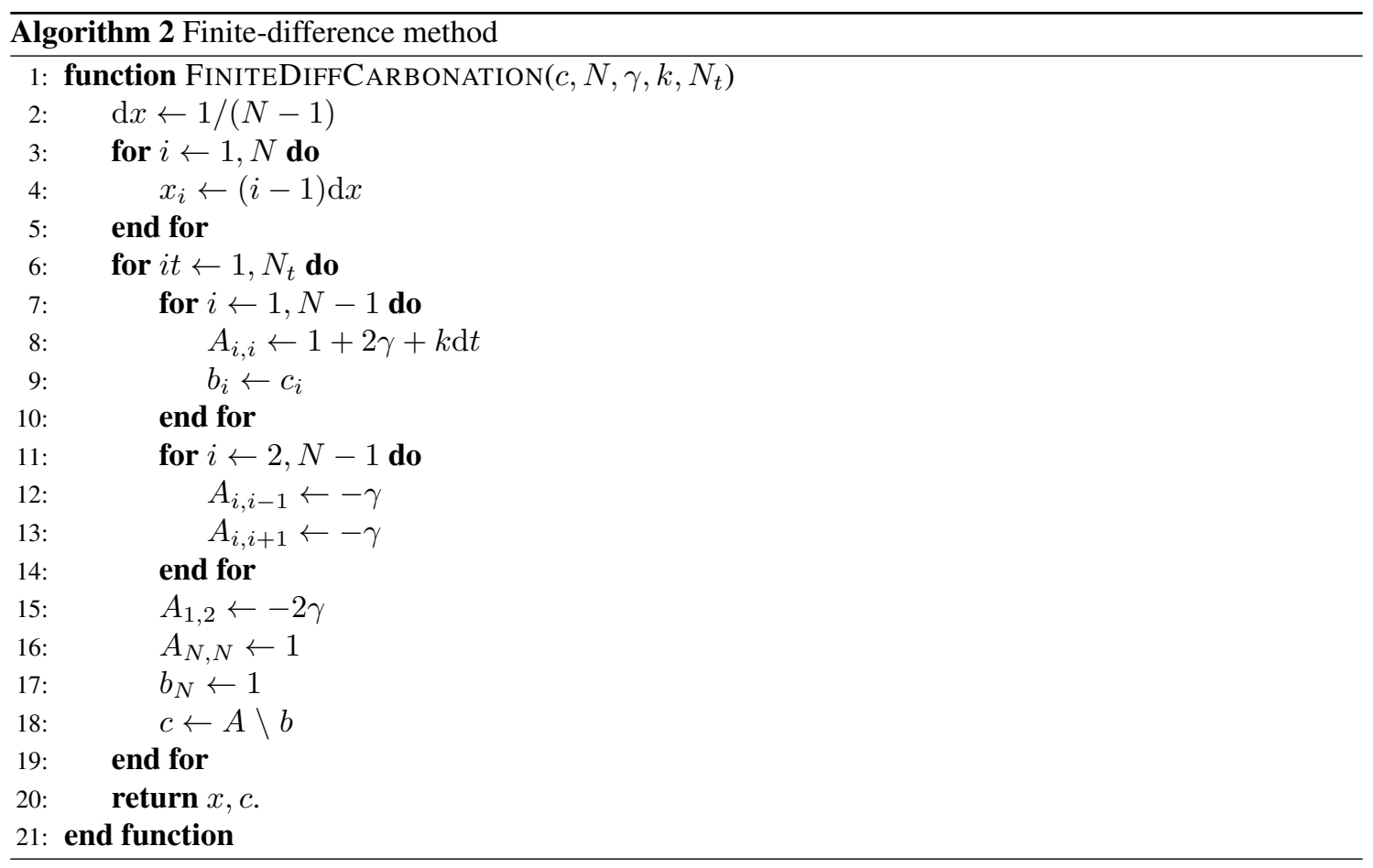

